\title{
ESTUDO ENZIMÁTICO DA DETERIORAÇÃO DE SEMENTES DE Melanoxylon brauna SUBMETIDAS AO ENVELHECIMENTO NATURAL E ACELERADO ${ }^{1}$
}

\author{
VIVIANA BORGES CORTE²; EDUARDO EUCLYDES DE LIMA E BORGES33 HELIO GARCIA LEITE; \\ BARBARA LUÍSA CORRADI PEREIRA 4; JOSÉ FRANCISCO DE CARVALHO GONÇALVES ${ }^{5}$
}

\begin{abstract}
RESUMO - Não há conhecimento específico para sementes florestais quanto aos processos metabólicos envolvidos durante o armazenamento, o que dificulta o estabelecimento de técnicas para sua conservação adequada. Assim, o objetivo do presente trabalho foi estudar a participação de enzimas do estresse oxidativo e metabolismo de lipídios durante o armazenamento ou envelhecimento acelerado. Sementes de brauna (Melanoxylon brauna - Leguminosae-Caesalpinoideae) foram envelhecidas naturalmente durante o armazenamento por $0,3,6,9$ e 12 meses em câmara fria e artificialmente (envelhecimento acelerado) durante $0,24,48,72$ e 96 horas, com objetivo de avaliar alterações na atividade das enzimas superóxido dismutase e catalase e nos teores de lipídios. Para isso, foram realizados testes de germinação, avaliadas a atividade enzimática e quantificados os teores de lipídios no eixo embrionário e nos cotilédones. O envelhecimento natural e acelerado afetou de forma semelhante o comportamento das sementes de brauna, promovendo redução do vigor. Embora os efeitos dos dois tipos de envelhecimento afetassem igualmente a germinação, o envelhecimento artificial a $45^{\circ} \mathrm{C}$ por 72 horas simula adequadamente o comportamento enzimático manifestado pelas sementes armazenadas por 12 meses em câmara fria. Houve semelhante redução gradativa das reservas de lipídios em ambos os sistemas de envelhecimento, mas sem correlação entre o armazenamento natural e o envelhecimento acelerado.
\end{abstract}

Termos para indexação: lipídio, estresse, armazenamento, sementes florestais, enzimas.

\section{ENZYMATIC STUDY OF THE DETERIORATION OF Melanoxylon brauna SEEDS AGED NATURALLY AND ARTIFICIALLY}

\begin{abstract}
There is no specific knowledge of forest tree seeds regarding the metabolic processes involved during storage which makes the establishment of techniques for their suitable conservation difficult. The object of the present research was to study the role of oxidative stress enzymes and fat metabolism during storage and artificial ageing. Seeds of Melanoxylon brauna - LeguminosaeCaesalpinodeae (brauna) were naturally aged during storage for $0,3,6,9$ and 12 months in a cold chamber, and artificially aged (accelerated ageing) during 0,24, 48, 72 and 96 hours, in order to evaluate the changes in the activity of the enzymes superoxide dismutase and catalase and also the oil content. Germination tests were made and the enzymatic activity and quantification of fat content were measured in the embryonary axis and cotyledons. The natural and accelerated ageing affected the behavior of the seeds in a similar manner causing a reduction in vigour. Although the artificial and
\end{abstract}

${ }^{1}$ Submetido em 29/05/2009. Aceito para publicação em 04/12/2009.

${ }^{2}$ Bióloga, Dra, Professora Substituta Departamento de Teorias e Práticas Institucionais da Universidade Federal do Espírito Santo, UFES, Vitória, ES, 29075-910. viviborgescorte@yahoo.com.br

${ }^{3}$ Eng. Florestais, professores Drs., Departamento de Eng. Florestal, UFV, av. P. H. Rolfs, 36570-000, Viçosa, MG, elborges@ufv.br
${ }^{4}$ Estudante de graduação, Dept. Eng. Florestal, UFV, av. P. H. Rolfs, 36570-000 Viçosa, MG, babicorradi@gmail.com

${ }^{5}$ Eng. Agr., Pesquisador Inst. Nac. Pesq. Amazônia (MCT-INPA), Lab. Fisiol. Bioq. Vegetal - INPA V/8, Av. Efigênio Sales, caixa postal 476, 69011-970, Manaus, AM.jfc@inpa.gov.br 
natural ageing of the seeds affected the germination in a similar way, the accelerated ageing at $45^{\circ} \mathrm{C}$ for 72 hours adequately simulated the enzymatic behavior as demonstrated by the seeds stored for 12 months in the cold chamber. There was a similar gradual reduction in the fat reserves in both ageing systems but without any correlation between natural storage and accelerated ageing.

Index terms: lipid, stress, storage, forest seeds, enzymes.

\section{INTRODUÇÃO}

Altas temperatura e umidade durante o armazenamento das sementes contribuem para a sua deterioração, por promoveremalterações degenerativascomoadesestabilização nas atividades de enzimas e a desestruturação e perda de integridade do sistema de membranas celulares, causada, principalmente, pela peroxidação de lipídios (Vieira et al., 1994) devido ao aumento das espécies reativas do oxigênio (EROs) (Del Rio et al., 1998). As células são dotadas de mecanismos protetores de defesa contra EROs, prevenindo a sua formação e promovendo a remoção das formas reativas produzidas (Alscher et al., 2002), como pelos sistemas antioxidantes enzimáticos (Arrigoni et al., 1992; Chaitanya et al., 2000; Tommasi et al., 2001; Bailly, 2004). Vários trabalhos têm sido realizados na tentativa de explicar a relação entre o envelhecimento de sementes durante o armazenamento e a peroxidação de lipídios (Wilson Jr. e McDonald Jr., 1986; Kalpana e Madhava Rao, 1996; Camargo et al., 2000), com respostas variáveis, de acordo com a espécie.

Durante o armazenamento de sementes de algodão (Goel e Sheoran, 2003) e soja (Sung e Chiu, 1995) observou-se que as atividades das enzimas catalase (CAT) e superóxido dismutase (SOD), reduziram progressivamente. Chang e Sung (1998) observaram redução na atividade de CAT em sementes de milho durante envelhecimento. Sung e Jeng (1994) concluíram que com o envelhecimento artificial de sementes de amendoim houve redução da atividade da SOD, entretanto a atividade da CAT não variou. Em sementes armazenadas de soja (Stewart e Bewley, 1980) e amendoim (Sung e Jeng, 1994) a atividade da SOD não foi detectada, enquanto CAT teve atividade detectada em eixo e cotilédones.

Observa-se variabilidade na resposta das diferentes espécies em relação ao uso do envelhecimento acelerado nos estudos do vigor e na deterioração das sementes. Alguns autores afirmam haver correlação entre envelhecimento natural e o acelerado, sendo os mecanismos promotores da deterioração os mesmos em ambas as situações, somente variando a velocidade com que ocorrem (Delouche e Baskin, 1973; Santos e Paula, 2007), ao passo que outros autores afirmam que o envelhecimento acelerado não reproduz de forma confiável os eventos metabólicos que acontecem durante o armazenamento, portanto não sendo recomendado como simulador do processo de envelhecimento natural (Bailly et al., 1996; Fanan et al., 2006).

Braúna preta (Melanoxylon brauna - LeguminosaeCaesalpinoideae) é árvore nativa conhecida pela qualidade e durabilidade de sua madeira. Ocorre na floresta atlântica, desde o sul da Bahia até São Paulo, Minas Gerais (Lorenzi, 1992), além dos estados de Goiás, Rio Grande do Norte, Mato Grosso, Maranhão e Piauí (IBAMA, 1992). Entretanto, devido à exploração excessiva e falta de replantios, a espécie está classificada como vulnerável, conforme a "lista oficial de flora ameaçada de extinção" (IBAMA, 1992).

Por isso, diante da escassez de estudos acerca do processo de deterioração de sementes dessa espécie, este trabalho objetivou quantificar e comparar as atividades das enzimas relacionadas ao estresse oxidativo, a germinação e as reservas de lipídio em sementes de Melanoxylon brauna durante o envelhecimento natural e acelerado.

\section{MATERIAL E MÉTODOS}

Foram utilizadas sementes de Melanoxylon brauna colhidas de 15 árvores na região de Viçosa, Minas Gerais, as quais foram misturadas, compondo um único lote. Os trabalhos foram conduzidos junto ao Laboratório de Sementes Florestais do Departamento de Engenharia Florestal da Universidade Federal de Viçosa. Durante o beneficiamento foram eliminadas as sementes imaturas, deterioradas ou danificadas. As sementes, contendo aproximadamente 10\% de umidade, foram armazenadas em embalagens de plástico dentro de caixas de papelão $(25 \times 22,5 \mathrm{~cm})$, a $20{ }^{\circ} \mathrm{C}$ e $60 \%$ de umidade relativa.

As análises bioquímicas e enzimáticas foram realizadas 
separadamente no eixo embrionário e nos cotilédones. As análises foram realizadas em sementes recém colhidas (sem armazenamento) usadas como controle, e a cada três meses durante 12 meses. Para o envelhecimento artificial, as sementes foram colocadas em caixas de plástico ("gerbox"), contendo $40 \mathrm{~mL}$ de água destilada, as quais foram colocadas em câmara de envelhecimento acelerado a 40 e $45^{\circ} \mathrm{C}$ e aproximadamente $100 \%$ de umidade relativa. Os tempos de envelhecimento foram de 0, 24, 48, 72 e 96 horas. As sementes foram mantidas separadas da água por tela de nylon $(5 \mathrm{~mm})$, onde as sementes foram dispostas uniformemente.

Germinação: foi determinada pela contagem diária das sementes germinadas no período de 10 dias. As sementes foram colocadas sobre duas folhas de papel de filtro tipo germitest umedecidas com água, em placas de Petri e mantidas em germinador a $25{ }^{\circ} \mathrm{C}$ e luz constantes, proporcionada por quatro lâmpadas de $20 \mathrm{~W}$, tipo luz do dia. Foram consideradas germinadas as sementes que emitiram radícula. $\mathrm{O}$ reumedecimento foi feito sempre que necessário. Os resultados foram expressos em porcentagem média. Foram utilizados cinco repetições de 20 sementes cada.

Teor de lipídios: a determinação do teor de lipídios foi realizada pelo método de Soxhlet, de extração a frio com éter de petróleo como solvente, conforme Silva (1990). Foram utilizadas três repetições de $1,0 \mathrm{~g}$.

\section{Extração das enzimas Catalase e Superóxido}

Dismutase: extratos enzimáticos brutos para as determinações das atividades da catalase (CAT) e da superóxido dismutase (SOD) foram obtidos, conforme Peixoto et al. (1999), pela maceração de $0,2 \mathrm{~g}$ de tecido vegetal de cotilédone ou eixo embrionário em $\mathrm{N}_{2}$ líquido, seguido da adição de 2,0 $\mathrm{mL}$ do seguinte meio de homogeneização: tampão fosfato de potássio $0,1 \mathrm{M}, \mathrm{pH}$ 6,8, ácido etilenodiaminotetracético (EDTA) 0,1 mM, fluoreto de fenilmetilsulfônico (PMSF) 1 $\mathrm{mM}$ e polivinilpolipirrolidona (PVPP) $1 \%(\mathrm{p} / \mathrm{v})$. Seguiu-se centrifugação a $12.000 \times \mathrm{g}$ por 15 minutos, a $4{ }^{\circ} \mathrm{C}$, obtendose um extrato enzimático bruto.

Determinação da atividade enzimática: a atividade da catalase foi determinada pela adição de $100 \mu \mathrm{L}$ do extrato enzimático bruto a $2,9 \mathrm{~mL}$ de um meio de reação constituído de tampão de fosfato de potássio $50 \mathrm{mM}$, pH 7,0 e $\mathrm{H}_{2} \mathrm{O}_{2}$ 12,5 mM (Havir e McHale, 1989). O decréscimo na absorbância a $240 \mathrm{~nm}$, à temperatura de $25^{\circ} \mathrm{C}$, foi medido durante $\mathrm{o}$ primeiro minuto de reação, sendo, a atividade da CAT determinada com base na inclinação da reta após o inicio da reação. A atividade enzimática foi calculada utilizando-se o coeficiente de extinção molar de $36 \mathrm{M} \mathrm{cm}^{-1}$ (Anderson et al.,

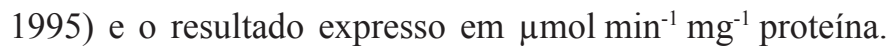
Foram utilizados quatro repetições com duplicatas.
A atividade da superóxido dismutase foi determinada pela adição de $30 \mu \mathrm{L}$ do extrato enzimático bruto de cotilédone e eixo embrionário a $2,97 \mathrm{~mL}$ de um meio de reação constituído de tampão fosfato de sódio $50 \mathrm{mM}, \mathrm{pH}$ 7,8 , contendo metionina $13 \mathrm{mM}$, azul de p-nitro tetrazólio (NBT) $75 \mu \mathrm{M}$, EDTA $0,1 \mathrm{mM}$ e riboflavina $2 \mu \mathrm{M}$ (Del Longo et al., 1993). A reação foi conduzida a $25^{\circ} \mathrm{C}$ numa câmara de reação sob iluminação de uma lâmpada fluorescente de 15 W mantida no interior de uma caixa fechada. Após 5 min de exposição à luz, a iluminação foi interrompida e a formazana azul produzida pela fotorredução do NBT foi medida a 560 nm (Giannopolitis e Ries, 1977). A absorbância a 560 nm, de um meio de reação exatamente igual ao anterior, mas mantido no escuro, por igual tempo, serviu de "branco" e foi subtraído da leitura da amostra que recebeu iluminação. Uma unidade de SOD foi definida como a quantidade da enzima necessária para inibir em $50 \%$ a fotorredução do NBT (Beauchamp e Fridovich, 1971). Foram utilizados quatro repetições com duplicatas.

Análise estatística: o delineamento experimental foi inteiramente ao acaso, com três a cinco repetições conforme o teste. Os resultados foram submetidos à análise estatística, utilizando-se o programa Statistica 8.0. Para a comparação das médias, adotou-se o teste de Tukey, a 5\% de probabilidade.

\section{RESULTADOS E DISCUSSÃO}

Houve redução da porcentagem de germinação das sementes de Melanoxylon brauna com o aumento do tempo de armazenamento (Figura 1a; Tabela 1). A frequência relativa evidencia o atraso de germinação com o deslocamento para a direita, com ênfase a partir dos seis meses de armazenamento (Figura 1b).

Ao contrario, sementes artificialmente envelhecidas a $40{ }^{\circ} \mathrm{C}$ mantiveram a germinação final até 96 horas de envelhecimento, com valores deste, próximos aos daquele de 12 meses do envelhecimento natural. As frequências da germinação nos tempos até 72 horas deslocaram-se para a esquerda, indicando maior velocidade de germinação. As sementes artificialmente envelhecidas por 72 horas mantiveram a mesma frequência, mas com valores menores, quando comparadas ao envelhecimento natural por 12 meses (Figuras 1c e 1d; Tabela 1). Esses resultados demonstram que a temperatura de $40{ }^{\circ} \mathrm{C}$ não foi eficiente para simular a aceleração do envelhecimento em sementes de Melanoxylon brauna, nas primeiras 72 horas. Nesse tempo de exposição, as sementes já estavam pré-embebidas. $\mathrm{O}$ avanço no processo de embebição somado à elevação da temperatura promoveu aceleração no metabolismo germinativo das sementes. 
Entretanto, com 96 horas, os efeitos negativos da deterioração começam a se manifestar com redução significativa na porcentagem de germinação e maior desuniformidade de germinação (Figuras 1c e 1d). Esse resultado evidencia que no envelhecimento artificial, a $40{ }^{\circ} \mathrm{C}$, ao contrário do
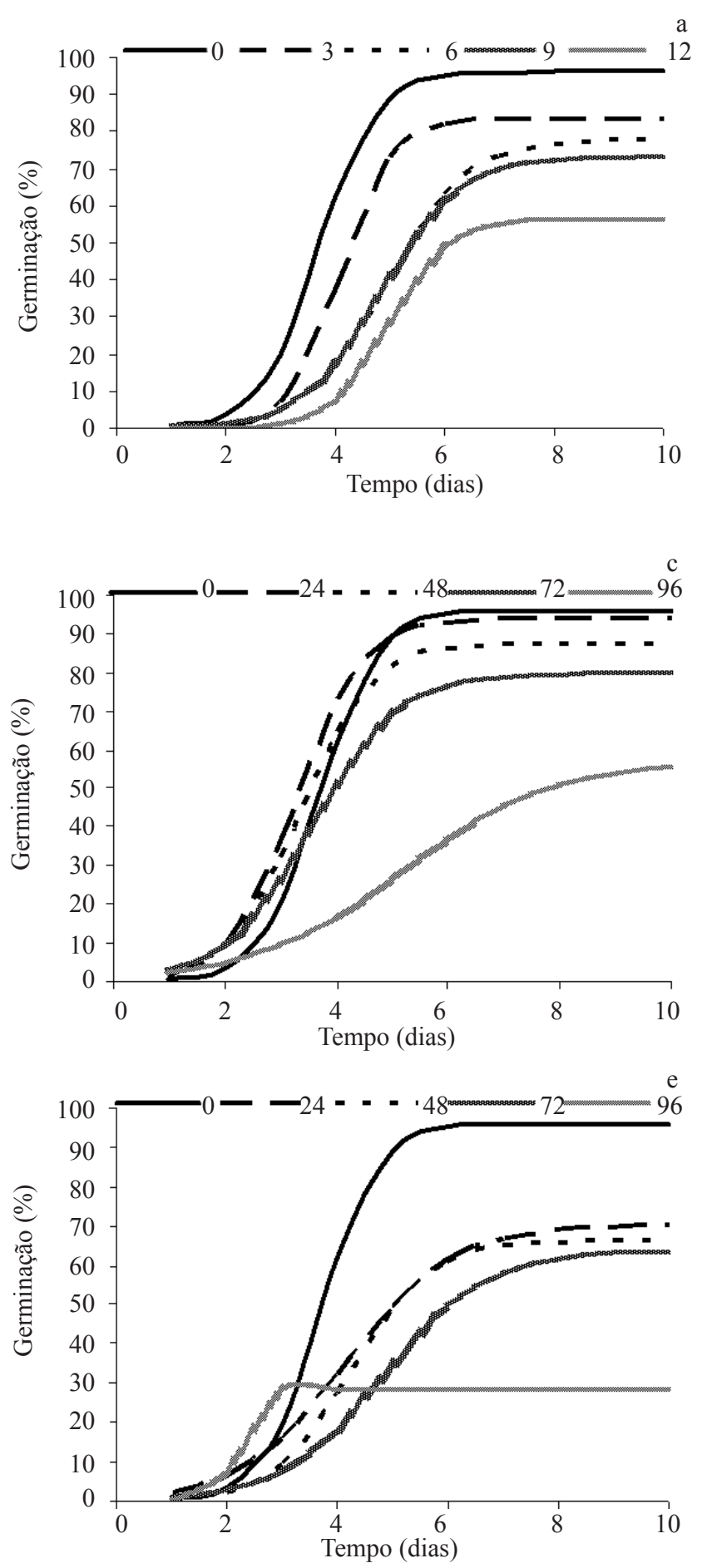

natural, a deterioração não se processa de forma gradativa com o aumento do envelhecimento. A temperatura de $40{ }^{\circ} \mathrm{C}$ e a umidade estimulou a germinação das sementes mais vigorosas, já em menor número, resultando no deslocamento da curva para a esquerda.
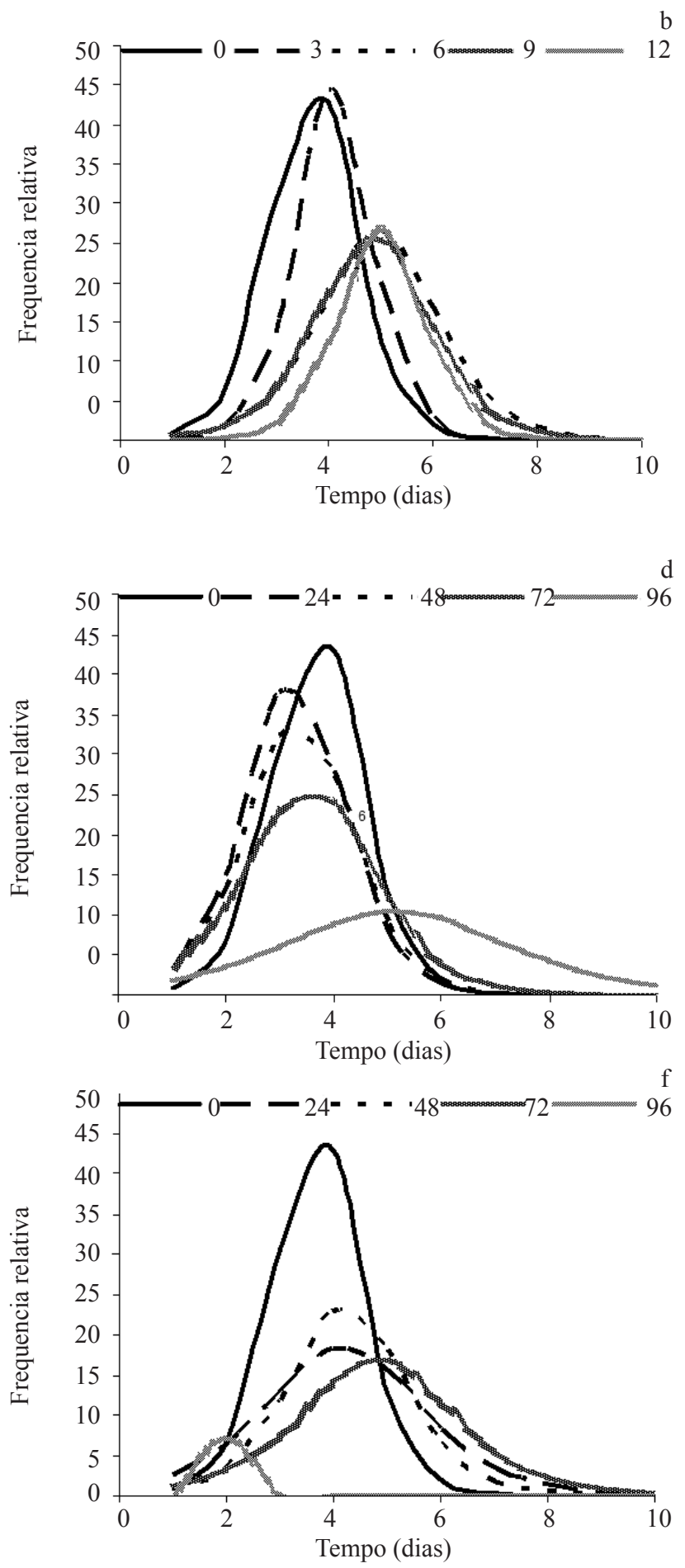

FIGURA 1. Porcentagem e frequência relativa de germinação das sementes de Melanoxylon brauna em função do tempo de envelhecimento natural (a - b) e acelerado a $40{ }^{\circ} \mathrm{C}(\mathrm{c}-\mathrm{d})$ e $45^{\circ} \mathrm{C}(\mathrm{e}-\mathrm{f})$. 
TABELA 1. Equações relativas à porcentagem de germinação após o envelhecimento natural e acelerado de sementes de Melanoxylon brauna. ( = Coeficiente de correlação entre os valores observados e os estimados ; $\mathrm{S}=$ Erro padrão residual).

\begin{tabular}{|c|c|c|}
\hline & Tratamento & Equação \\
\hline \multirow{13}{*}{ 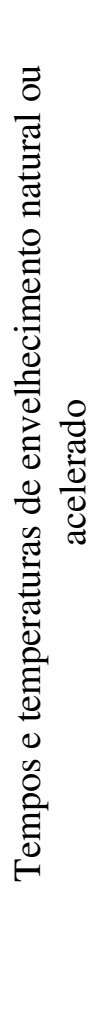 } & Tempo zero (T0) & $\mathrm{Y}=96,10\left(1+1332,60 \ell^{-1,95 x}\right)^{-1} R y \hat{y}=0,9992 ; \mathrm{S}=1,8959$ \\
\hline & 3 meses & $\mathrm{Y}=83,45\left(1+7137,42 \ell^{-2,16 x}\right)^{-1} R y \hat{y}=0,9991 ; \mathrm{S}=1,8309$ \\
\hline & 6 meses & $Y=77,82\left(1+891,63 \ell^{-1,37 x}\right)^{-1} R y \hat{y}=0,9958 ; S=3,6578$ \\
\hline & 9 meses & $Y=73,24\left(1+915,31 \ell^{-1,41 x}\right)^{-1} R y \hat{y}=0,9933 ; S=4,3697$ \\
\hline & 12 meses & $Y=56,36\left(1+403291,75 \ell^{-1,89 x}\right)^{-1} R y \hat{y}=0,9998 ; S=0,5502$ \\
\hline & 24 horas $40^{\circ} \mathrm{C}$ & $Y=94,02\left(1+253,64 \ell^{-1,69 x}\right)^{-1} R y \hat{y}=0,9980 ; S=2,7067$ \\
\hline & 48 horas $40^{\circ} \mathrm{C}$ & $\mathrm{Y}=87,72\left(1+214,0 \ell^{-1,60 \mathrm{x}}\right)^{-1} R y \hat{y}=0,9984 ; \mathrm{S}=2,2055$ \\
\hline & 72 horas $40^{\circ} \mathrm{C}$ & $\mathrm{Y}=79,78\left(1+98,87 \ell^{-1,29 x}\right)^{-1} R y \hat{y}=0,9918 ; \mathrm{S}=4,6529$ \\
\hline & 96 horas $40^{\circ} \mathrm{C}$ & $\mathrm{Y}=57,19\left(1+46,37 \ell^{-0,74 \mathrm{x}}\right)^{-1} R y \hat{y}=0,9970 ; \mathrm{S}=1,8582$ \\
\hline & 24 horas $45^{\circ} \mathrm{C}$ & $\mathrm{Y}=70,45\left(1+76,70 \ell^{-1,04 x}\right)^{-1} R y \hat{y}=0,9932 ; \mathrm{S}=3,8070$ \\
\hline & 48 horas $45^{\circ} \mathrm{C}$ & $Y=66,16\left(1+420,30 \ell^{-1,42 x}\right)^{-1} R y \hat{y}=0,9962 ; S=2,8907$ \\
\hline & 72 horas $45^{\circ} \mathrm{C}$ & $\mathrm{Y}=63,83\left(1+175,51 \ell^{-1,07 x}\right)^{-1} R y \hat{y}=0,9944 ; \mathrm{S}=3,2829$ \\
\hline & 96 horas $45^{\circ} \mathrm{C}$ & $\mathrm{Y}=28,43\left(1+442,60 \ell^{-1,28 x}\right)^{-1} R y \hat{y}=0,9965 ; \mathrm{S}=1,1821$ \\
\hline
\end{tabular}

$\mathrm{O}$ envelhecimento artificial a $45{ }^{\circ} \mathrm{C}$ afetou a capacidade germinativa das sementes já nas primeiras 24 horas de exposição, tendo maior redução com 96 horas de envelhecimento (Figura 1e). As diferenças nos efeitos dessas temperaturas já são sentidas nas primeiras 24 horas de envelhecimento, com maior deterioração naquelas mantidas a $45^{\circ} \mathrm{C}$, cujas frequências estão deslocadas para a direita (Figuras 1d e 1f).

Dentre as alterações que ocorrem durante a deterioração, segundo McDonald (1999), está a produção de radicais livres ou espécies reativas de oxigênio (ERO) que promovem modificações na estrutura das enzimas, além da degradação do sistema de síntese de novas enzimas. Os danos oxidativos, relacionam a perda da capacidade germinativa de sementes com a diminuição da eficiência dos sistemas antioxidantes (Hendry, 1993; Sung, 1996; Chaitanya et al. 2000). Considerando que há compartimentos nas sementes mais sensíveis à deterioração do que outros (Das e Sem-Mandi, 1992; Marcos Filho,
2005), foram estudados separadamente o embrião e os cotilédones. Com base nos resultados de germinação elegeu-se a temperatura de $45{ }^{\circ} \mathrm{C}$ de envelhecimento acelerado para as análises enzimáticas.

A enzima SOD apresentou no eixo embrionário e nos cotilédones, nas sementes recém colhidas (tempo zero), estatisticamente, o mesmo nível de atividade, com posterior aumento apenas nos cotilédones após 12 meses de armazenamento (Figura 2a). No eixo embrionário, a atividade foi mantida inalterada, mesmo com a redução na germinação. A atividade da SOD nas primeiras 24 horas de envelhecimento acelerado aumentou no eixo embrionário, mantendo-se estável até 48 horas e decrescendo em 72 horas, sugerindo aumento na proteção contra danos celulares. Não se detectou atividade da SOD no eixo em 96 horas de envelhecimento, embora ainda houvesse germinação. Provavelmente as poucas sementes vigorosas não foram em número suficiente para se ter volumes do extrato adequado para a detecção. 

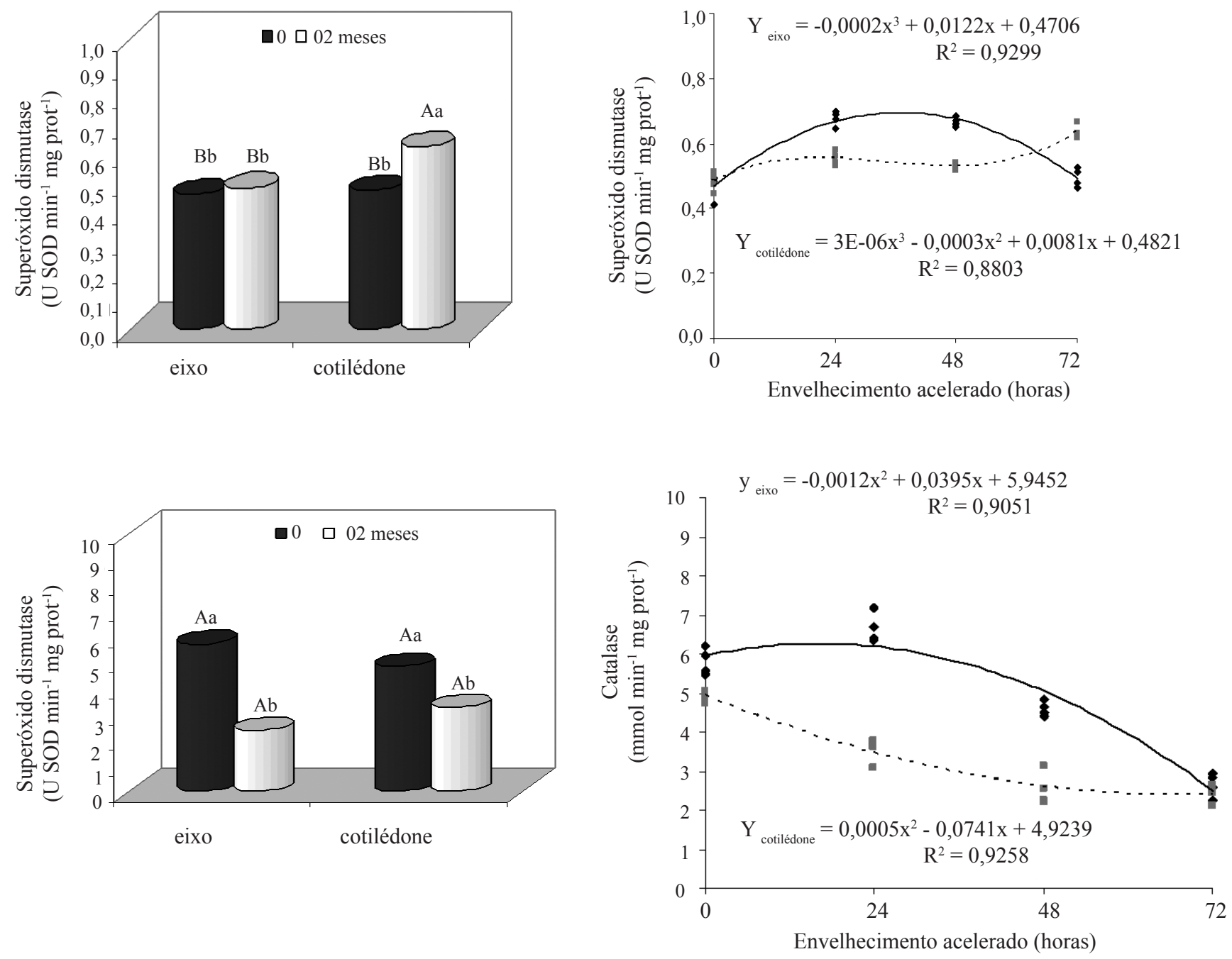

FIGURA 2. Atividade das enzimas superóxido dismutase (a - b) e catalase (c - d) em sementes de Melanoxylon brauna, em função do envelhecimento natural e artificial. — eixo embrionário; ---- cotilédone. Letras maiúsculas comparam médias entre compartimentos, e letras minúsculas comparam tempos inicial e final pelo Teste $\mathrm{F}$.

O aumento significativo na atividade da SOD nos cotilédones no envelhecimento natural sugere maior atividade metabólica. Embora a germinação decresça, há ainda mobilização de reservas para manter a atividade de respiração e produção de estrutura de carbono no eixo, como a de lipídios, por exemplo, predominantes nos cotilédones. A atividade da enzima SOD mantém-se estatisticamente estável até 48 horas e tende a aumentar entre 48 e 72 horas de exposição ao envelhecimento acelerado (Figura 2b), tal como o observado aos 12 meses de armazenamento, em que houve aumento na atividade da enzima (Figura 2a). Dessa forma, supõe-se tratar de isoenzima diferente daquela do embrião. Supõe-se também que a manutenção da atividade implica que o metabolismo é mais lento do que no eixo nos tempos de 24 e 48 horas. $\mathrm{O}$ aumento em 72 horas significaria maior atividade metabólica ou mudança do substrato, sendo utilizado, com predominância, aqueles que produzem EROs mais intensamente.

As SOD são um grupo de enzimas encontradas no citoplasma celular e matriz mitocondrial, constituindo-se na primeira linha de defesa contra EROs (Alscher et al., 2002). Assim, as SODs estão entre os mais importantes sistemas de defesa, quando acopladas a rotas de eventos necessários à completa detoxificação das EROs (Alscher et al., 2002). $\mathrm{O}$ peróxido de hidrogênio formado como subproduto da atividade da SOD, apesar de menos reativo, em altas 
concentrações torna-se tóxico, pois pode reagir formando radicais hidroxila (Bowler et al., 1992) que causam peroxidação de lipídios.

A CAT apresentou decréscimos significativos tanto no eixo, quanto nos cotilédones no envelhecimento natural (Figura 2c). A atividade foi alta no tempo zero, com decréscimos significativos, em ambas as enzimas, em ambos os compartimentos após 12 meses. É possível que tal comportamento esteja relacionado à eliminação de EROs, formados durante o desenvolvimento da sementes, nos 12 meses de armazenamento. A estabilização da atividade da enzima a partir de 48 horas de envelhecimento acelerado foi utilizado como indicador para a não realização das avaliações em 96 horas, especialmente quando o teor de lipídios estabilizou o seu decréscimo a partir de 24 horas de envelhecimento acelerado.

Em sementes de Ginkgo biloba armazenadas a $4{ }^{\circ} \mathrm{C}$ a atividade da catalase manteve-se estável no embrião e endosperma, reduzindo significativamente sua atividade apenas aos 12 meses, ao passo que quando expostas a $25^{\circ} \mathrm{C}$ essa queda na atividade foi antecipada para os 6 meses de armazenamento (Tommasi et al., 2006).

Assim, percebe-se que há similaridades nos comportamentos das duas enzimas, tanto no envelhecimento natural, quanto no artificial, em ambos os compartimentos permitindo afirmar que no aspecto de processo de desintoxicação, o envelhecimento artificial possui mecanismo similar àquele do envelhecimento natural, da mesma forma que a utilização de reservas de lipídios (Figura 3). A aparente ineficiência no sistema de eliminação de EROs, baseado na atividade de ambas as enzimas, tanto no envelhecimento natural quanto artificial, pela falta de sincronização entre SOD e CAT pode estar sendo compensada pela atuação de substâncias antioxidantes como o ácido ascórbico ou piridoxina (vitamina B6) (Dolatabadian e Modarressanavy, 2008).
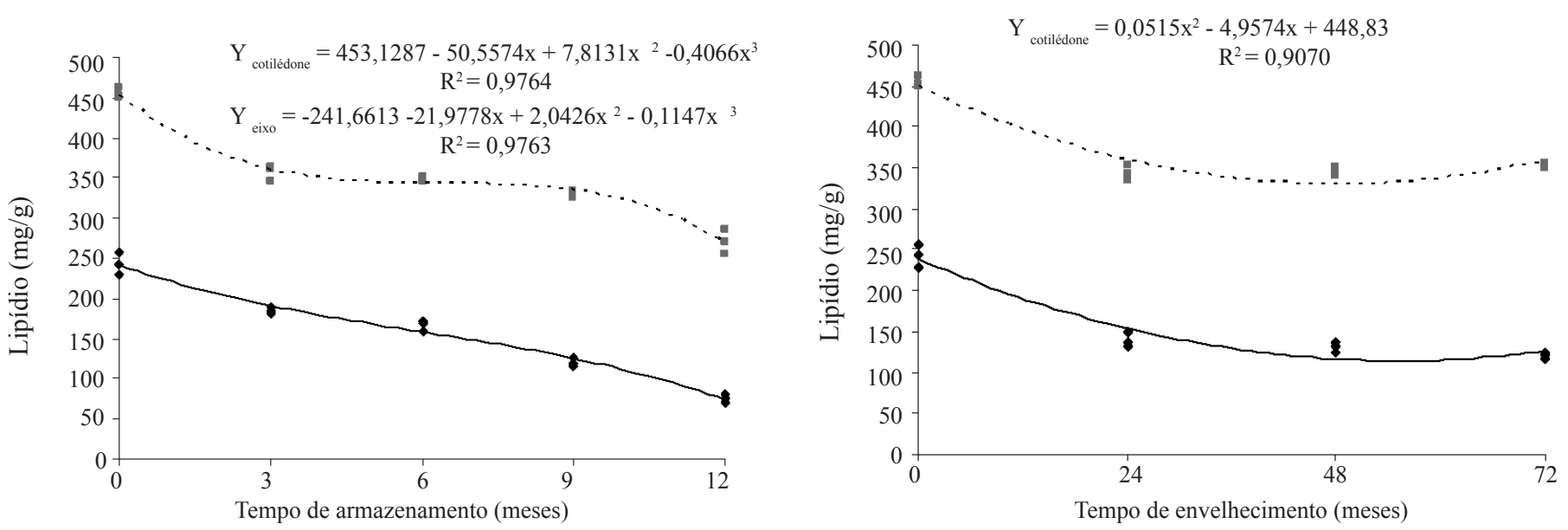

\section{FIGURA 3. Teor de lipídios de sementes de Melanoxylon brauna, em função do envelhecimento natural (a) e artificial (b). - eixo embrionário; ---" cotilédone.}

Houve redução progressiva no teor de lipídios no eixo embrionário e cotilédones de sementes de M. brauna com o aumentodadeterioraçãodesementesarmazenadas. Resultados semelhantes foram observados tanto no armazenamento por 12 meses (Figura 3a) quanto no envelhecimento artificial por 72 horas (Figura 3b). Neste, estabilizou a partir 24 horas, em ambos os compartimentos, justificando a não quantificação do teor de lipídios em 96 horas. O aumento da peroxidação de lipídios, mediado por radicais livres e peróxidos é uma das prováveis razões para a perda da viabilidade de sementes durante o armazenamento.

\section{CONCLUSÕES}

O envelhecimento artificial a $45^{\circ} \mathrm{C}$ por 72 horas simula os resultados fisiológicos e bioquímicos da deterioração ocorrida em sementes de Melanoxylon brauna armazenadas em câmara fria a $5{ }^{\circ} \mathrm{C}$ por 12 meses. 
As atividades das enzimas Superóxido dismutase (SOD) e catalase (CAT) foram semelhantes tanto no envelhecimento natural quanto no artificial.

Houve redução da germinação e dos teores de lipídios nas sementes envelhecidas natural e artificialmente.

\section{REFERÊNCIAS}

ALSCHER, RG; ERTURK, N; HEALTH, LS. Role of superoxide dismutases (SODs) in controlling oxidative stress in plants. Journal of experimental Botany, Antioxidants and Reactive Oxygen Species in Plants Special Issue, v.53, n. 372, p.1331-1341, 2002.

ANDERSON M. D; PRASAD, T. K.; STEWART, C. R. Changes in isozyme profiles of catalase, peroxidase, and glutathione reductase during acclimation to chilling in mesocotyls of maize seedlings. Plant Physiology. v.109, p.1247-1257, 1995.

ARRIGONI, O.; DE GARA, L.; TOMMASI, F.; LISO, R. Changes in the ascorbate system during seed development of Vicia faba L., Plant Physiology, v. 99, n. 1, p. 235-238, 1992.

BAILLY, C; BENAMAR, A; CORBINEAU, F; COME, $D$. Changes in malondialdehyde content and in superoxide dismutase, catalase and glutathione reductase activities in sunflower seeds as related to deterioration during accelerated aging. Physiologia Plantarum, v. 97, p. 104-110, 1996.

BAILLY, C. Active oxygen species and antioxidants in seed biology. Seed Science Research, v.14, p. 93-107, 2004.

BEAUCHAMP C., FRIDOVICH I. Superoxide dismutase improved assays and assay applicable to acrylamide gels. Analytical Biochemistry, v. 44, p. 276-287, 1971.

BOWLER, C; VAN MONTAGU, M; INZÉ, D. Superoxide dismutase and stress tolerance. Annual Review Plant Physiology and Plant Molecular Biology, v. 43, p. 83116, 1992.

CAMARGO, M.L.P.; MORI, E.S.; MELLO, E.J.; ODA, S.; LIMA, G.P. Atividade enzimática em plântulas de Eucalyptus grandis provenientes de sementes envelhecidas artificialmente e naturalmente. Ciência Florestal, v. 10, n. 2, p. 113-122, 2000.

CHAITANYA, K.S.K.; NAITHANI, T.; NAITHANI, S.C. Ascorbic acid metabolism in ageing recalcitrant sal (Shorea robusta Gaertn. F.) seeds. Indian Journal Experimental of Botany, v. 38, p. 1031-1035, 2000.
CHANG, S.M.; SUNG, J.M. Deteriorative changes in primed sweet corn seeds during storage. Seed Science and Technology, v. 26, p.613-626, 1998.

DAS, G.; SEM-MANDI, S. Scutellar amylase activity in naturally aged and accelerated aged wheat seeds. Annals of Botany, v.69, p.479-501,1992.

DEL LONGO, O.T.; GONZÁLES, C.A.; PASTORI, G.M.; TRIPPI, V.S. Antioxidant defenses under hyperoxygenic and hyperosmotic conditions in leaves of two lines of maize with differential sensitivity to drought. Plant Cell Physiology, v.34, p.1023-1028, 1993.

DEL RIO, LA; PASTORI, GM; PALMA, JM; SANDALIO, LM; SEVILLA, F; CORPAS, FJ; JIMÉNEZ, A; LÓPEZHUERTAS, E; HERNÁNDEZ, JA. The activated oxygen role of peroxisomes in senescence. Plant Physiology, v.116, p.1195-1200, 1998.

DELOUCHE, J. C.; BASKIN, C. C. Accelerated aging techniques for predicting the relative storability of seed lots. Seed Science and Technology, v. 1, n. 2, p. 427-452, 1973.

DOLATABADIAN, A.; MODARRESSANAVY, S. A. M. Effect of the ascorbic acid, pyridoxine and hydrogen peroxide treatments on germination, catalase activity, protein and malondialdehyde content of three oil seeds. Notulae Botanicae Horti Agrobotanici, v.36, n.2, p.6166, 2008.

FANAN, S.; P.F. MEDINA ; T. C. LIMA ; J.M. FILHO . Avaliação do vigor de sementes de trigo pelos testes de envelhecimento acelerado e de frio. Revista Brasileira de Sementes, v. 28, n. 1, p. 152-158, 2006.

GIANNOPOLITIS, C.N.; RIES, S.K. Superoxide dismutases. Plant Physiology, v. 59, p.309-314, 1977.

GOEL, A; SHEORAN. Lipid peroxidation and peroxidescavenging enzymes in cotton seeds under natural ageing. Biologia Plantarum, v. 46, n. 3, p. 429-434, 2003.

HAVIR, E.; McHALE, N. A. A Regulation of Catalase Activity in Leaves of Nicotiana sylvestris by High $\mathrm{CO}_{2}$ Plant Physiology, v.89, n.3, p.952-957, 1989.

HENDRY, G.A.F. Oxygen, free radical processes and seed longevity. Seed Science Research., v.3, p.141-153, 1993.

IBAMA - Lista oficial de Flora ameaçada de extinção. 1992. Disponível em: <http://www.ibama.gov.br/flora $>$. Acesso em: 5/02/2008. 
KALPANA, R.; MADHAVA RAO, K.V. Absence of the role of lipid peroxidation during accelerated ageing of seeds of pigeonpea (Cajanus cajan (L.) Millsp.) cultivars. Seed Science and Technology, v.22, p.253$260,1996$.

LORENZI, H. Árvores brasileiras: manual de identificação e cultivo de plantas arbóreas nativas do Brasil. Nova Odessa: Plantarum, 1992. 384p.

MARCOS FILHO, J. M. Fisiologia de sementes de plantas cultivadas. Piracicaba: FEALQ, 2005. 495 p.

McDONALD, M. D. Seed deterioration, physiology, repair and assessment. Seed Science and Technology, v.22, n.3, p.531-539, 1999.

PEIXOTO, P.H.P.; CAMBRAIA, J.; SANT'ANNA, R.; MOSQUIN, P.R.; MOREIRA, M.A. Aluminium effects on lipid peroxidation and on the activities of enzymes of oxidative metabolism in sorghum. Revista Brasileira de Fisiologia Vegetal, v.11, n.3, p.137-143, 1999.

SANTOS, S. R. G.; PAULA, R. C. Teste de envelhecimento acelerado para avaliação do vigor de lotes de sementes de Sebastiania commersoniana (Baill.) Smith \& Downs (branquilho) - Euphorbiaceae. Revista do Instituto Florestal, v.19, n.1, p.1-12, 2007.

SILVA, D.J. Análise de alimentos (métodos químicos e biológicos). Viçosa: Imprensa Universitária, 1990. 165 p.

STEWART, R.R.; BEWLEY, J.D. Lipid peroxidation associated with accelerated aging of soybean axes. Plant
Physiology, v.65, n.2, p.245-248, 1980.

SUNG, J.M.; CHIU, K.Y. Hydration effect on seedling emergence strength of watermelon seeds differing in ploidy. Plant Science, v. 110, p.21-26, 1995.

SUNG, J.M.; JENG, T.L. Lipid peroxidation and peroxidescavenging enzymes associated with accelerated ageing of peanut seed. Physiologia Plantarum, v. 91, p. 51-55, 1994.

SUNG, JM. Lipid peroxidation and peroxide-scavenging in soybean seeds during aging. Physiologia Plantarum, v. 97, p. 85-89, 1996.

TOMMASI, F.; PACIOLLA, C.; PINTO, M.C.; GARA, L.D. A comparative study of glutathione and ascorbate metabolism during germination of Pinus pinea L. seeds. Journal of Experimental Botany, v. 52, p.1647-1654, 2001.

TOMMASI, F.; PACIOLLA, C.; PINTO, M.C.; GARA, L.D. Effects of storage temperature on viability, germination and antioxidant metabolism in Ginkgo biloba L. seeds. Plant Physiology and Biochemistry, v.44, p.359-368, 2006.

VIEIRA, R.D.; CARVALHO, N.M.; SADER, R. Testes de vigor e suas possibilidades de uso. In: VIEIRA, R.D.; CARVALHO, N.M. (Ed.). Teste de vigor em sementes. Jaboticabal: FUNEP, 1994. p.31-47.

WILSON Jr., D.O.; McDONALD Jr., M.B. The lipid peroxidation model of seed ageing. Seed Science and Technology, v.14, n.2, p.269-300, 1986. 